\title{
Sociocultural aspect in creating architectural space of medical facilities for children with disorders and disabilities \\ Barkovskaya A. ${ }^{1}$, Shagieva E. ${ }^{2}$ (Russian Federation) \\ Социокультурные особенности формирования архитектурного пространства для медицинской деятельности для детей с различными заболеваниями Барковская А. Ю. ${ }^{1}$ Шагиева Е. В. ${ }^{2}$ (Российская Федерация)
}

\author{
'Барковская Анна Юрьевна / Barkovskaya Аппа - кандидат философских наук, доцент, \\ кафедра философии, сочиологии и психологии; \\ ${ }^{2}$ Шагиева Елизавета Владимировна/Shagieva Elizaveta-магистрант, \\ направление: градостроительство, \\ Институт архитектуры и строительства \\ Волгоградский государственный технический университет, г. Волгоград
}

\begin{abstract}
Аннотация: в статье рассматриваются социокультурные потребности детей-пациентов и их родителей, и способь организации архитектурного пространства для реализаџии медицинской деятельности с их учетом. Архитектурное пространство современных российских медицинских учреждений педиатрического профиля анализируется как часть сочиильного пространства медицины, которое является полем сочиального взаимодействия, способного улучиить качество жизни больных детей и их семей.

Abstract: the purpose of this article is to develop into the nature of sociocultural needs of children patients ans their parents, as well as to examine methods of creating architectural space of medical facilities paying attention to the special needs of the children. The article analyzes architectural space of modern Russian medical facilities with pediatric specialty services as a component of social space of medicine. Moreover, the article discusses how social space of medicine, being a part of social interation, can improve the quality of life of children with different disorders and their families.
\end{abstract}

Ключевые слова: архитектурное пространство, медиџинские учреждения для детей, соииокультурные потребности, сочиальное пространство медицины.

Keywords: architectural space, medical facilities for children, sociocultural needs, social space of medicine.

В современном российском обществе формирование архитектурного пространства для медицинской деятельности с учетом специфических требований пациентов, максимально учитывающих их возраст, характер патологии, социально-психологические особенности и социокультурные потребности является актуальной задачей [1, с. 68]. В связи с масштабным реформированием системы здравоохранения, актуализацией индивидуального подхода к строительству и утверждением гуманистической парадигмы, акцентирующей внимание на том, что архитектура и дизайн медицинских зданий, в первую очередь, служат больному человеку и при этом учитывают потребности всех взаимодействующих в социальном пространстве медицины субъектов, они стали преображаться и носить «субъективный» характер.

Особого внимания заслуживает организация архитектурного пространства для больных детей, которые, будучи впечатлительнее, чем взрослые, все воспринимают острее. Если взрослые способны оценить пользу лечебных процедур и медицинских действий позитивно, адекватно воспринять ситуацию лечения, медицинский персонал, несмотря на пережитую боль и неприятные ощущения, то дети при дефиците смысловой регуляции, чаше испытывают боль, страх, дистресс, вызванные заболеванием, медицинскими манипуляциями или одним видом белых стен и людей в белых халатах. Необходимо, чтобы архитектурное пространство медицинских учреждений вызывало у детей положительные эмоции, радовало, отвлекало от физических и душевных страданий. В случае длительного лечения, реабилитации после перенесенных заболеваний оно должно создавать возможности для личностного развития ребенка, пространство для игры и обучения. В идеале, чтобы больному ребенку было комфортно, нужно создать среду, в которой он, играя, забывал о том, что он в больнице. Согласно теоретическим положениям, выдвинутым известным психологом Л. С. Выготским, среду, находящуюся вокруг ребенка, нужно считать «не обстановкой», а источником развития и «приглашающей силой» [2, с. 368]. Поэтому возрастает роль различных факторов в его оптимизации, в частности, новых форм социального взаимодействия в медицине, которые находят отражение в архитектурном пространстве. Способы его организации для больных детей мы и рассмотрим в настоящей статье.

Дети и подростки относятся к наиболее уязвимым группам, подверженным последствиям того, что их нужды в области здоровья остаются неудовлетворенными, около 40\% груза заболеваний приходится именно на них. Состояние здоровья детского населения России, а его верхняя возрастная граница по законодательству с 2001 г. расширена до 17 лет включительно, имеет явно негативные тенденции. По данным официальной статистики, отмечается рост первичной заболеваемости детей в возрасте 0-14 лет, который сказывается на динамике показателей общей заболеваемости, которые за период 2002-2010 гг. увеличились на 21,5\%. Так, за указанный период заболеваемость новообразованиями увеличилась на $62,1 \%$, врожденными аномалиями развития - на $42,5 \%$, болезнями органов дыхания - на $36 \%$, нервной системы - на 
31,3\%, кожи и подкожной клетчатки - на 20\%, болезнями мочеполовой системы - на 17,8\% [3, с. 4]. Наиболее ранимой группой являются длительно и часто болеющие дети и подростки. Установлено, что удельный вес этой группы в зависимости от возраста колеблется от 15 до 30\% от общего числа детей. За счет данной группы сохраняется высокий уровень заболеваемости детского населения и подростков [4, с. 21]. Это требует считать детей не просто статистически значимой социальной группой, имеющей те же права на доступную и комфортную среду для получения медицинской помощи или услуги, что и остальное население, а нуждающуюся в приоритетном удовлетворении ее потребностей в сфере медицинской деятельности.

Антропометрические, физиологические и психологические особенности больных детей предполагают другие эргономические требования к среде, нежели предназначенной для взрослых людей. При проектировании предметной среды должны учитываться отличительные особенности различных групп больных детей не только по возрасту, но и по мобильности, тяжести и характеру заболеваний. В современных условиях необходимо формирование архитектурного пространства не только для лечения, но и для интенсивной реабилитационной помощи детям с социально значимыми заболеваниями, а также для паллиативной помощи, позволяющей улучшить качество жизни детей-пациентов и их семей, столкнувшихся с проблемами угрожающего жизни заболевания.

Здания медицинских учреждений для детей находятся в постоянной зависимости от изменяющихся с течением времени требований общества и государства к лечению, воспитанию и обучению детей. Изучение факторов, влияющих на изменение данных требований, позволило В. О. Мосину разделить их на внешние $u$ внутренние [5, с. 8]. Внешние факторы (социокультурный, общественно-правовой, социальноэкономический) представляют собой средовую оболочку, в условиях которой формируются требования в направлении актуализации лечебно-восстановительных и учебно-воспитательных процессов детей. Внутренние факторы (медико-социальные, психологические, педагогические, типологические, антропометрические, эргономические) определяют требования к планировочному решению зданий, а также к качественному насыщению архитектурного пространства.

Длительное пребывание ребенка в больничном стационаре в отрыве от близких людей и от дома может приводить к эффекту госпитализма, под которым понимаются неблагоприятные, в первую очередь психологические и пространственные условия больничной среды и результаты их действия на психическое и физическое состояние пациента. Австро-американский психоаналитик Р. Спитс, который ввел в научный оборот понятие «госпитализм», к его симптомам относил: замедление психического и физического развития, отставание в овладении собственным телом и языком, пониженный уровень адаптации к окружению, ослабленную сопротивляемость к инфекциям, отмечая при этом, что последствия являются долговременными и зачастую необратимыми [6, с. 512]. Снизить негативные последствия госпитализма возможно изменив не только организационные методы оказания медицинской помощи, но и посредством архитектурно-планировочных и дизайнерских решений пространственной среды для реализации медицинской деятельности.

Вот почему стены детских отделений все чаще украшают яркие веселые рисунки, создаются специальные игровые комнаты, а врачи стали использовать медицинскую одежду, отличную от, привычного и так пугающего детей белого цвета, иногда и вовсе дополняя ее шапочками с забавными детскими принтами. Помимо создания игровых комнат, само пространство обычных коридоров и холлов может стать элементом игры. Например, пост медсестры можно превратить в корабль, а вокруг него выложить цветной пол, изображающий волны, или в центральном холле соорудить карусель. Предметная среда, там, где это возможно с учетом санитарно-эпидемиологического и лечебно-охранительного режимов, наполняется предметами, характерными для домашней обстановки: ярким постельным бельём, игрушками, мягкой мебелью, комнатными цветами, аквариумами и даже «живыми» уголками. Непосредственное пребывание в больнице вместе с маленьким пациентом родных ему людей, несомненно, улучшающее процесс лечения, требует учета и их потребностей. В нашей стране эта проблема еще не решена повсеместно, во многих больницах матери вынуждены проводить долгие месяцы около своих болеющих детей в совершенно невыносимых социально-бытовых условиях.

Рассмотрим, как меняются потребности в социальном пространстве медицины и главное, как они эффективно реализованы в архитектурном пространстве.

Научно-практический центр медицинской помощи детям с пороками развития черепно-лицевой области и врожденными заболеваниями нервной системы г. Москва, 2005 г. Более известен как научнопрактический центр помощи детям-инвалидам в Солнцево. Центр создавался по аналогу подобных комплексов в Голландии и Германии. Стационар центра рассчитан на 345 коек. 


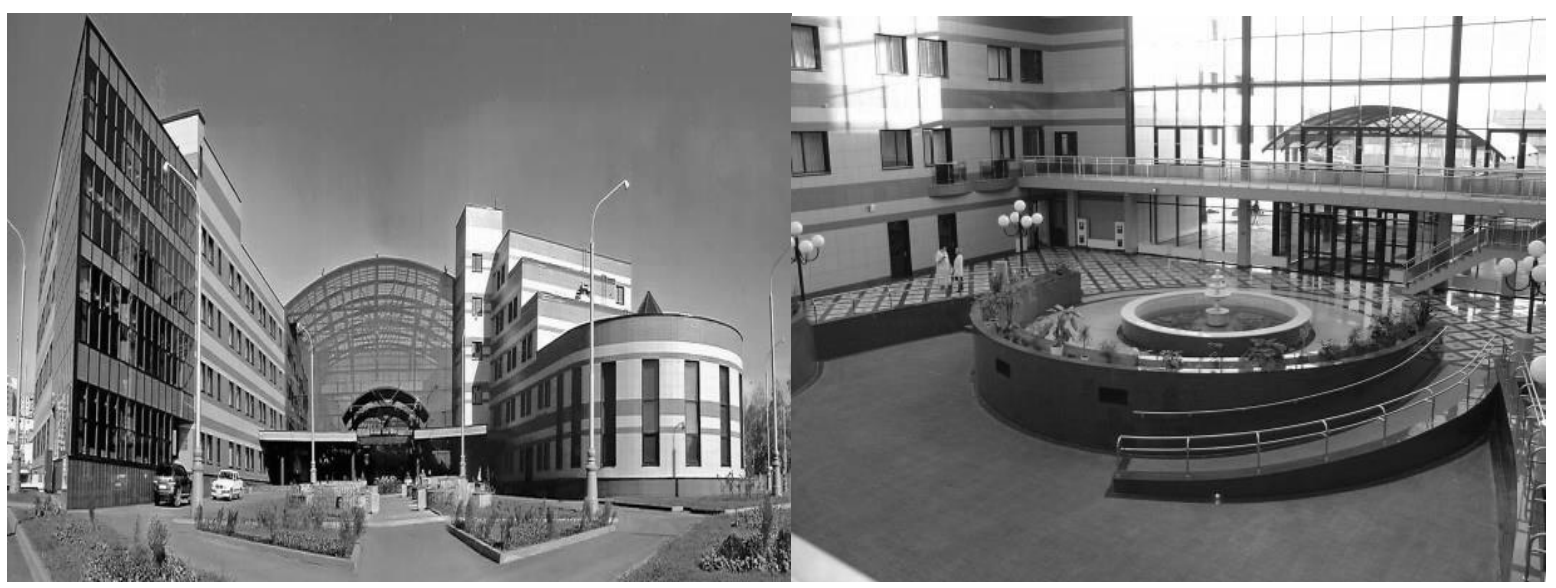

Рис. 1. НПЦ в Солнцево

Внешние фасады палатного и лечебного блоков решены без излишней вычурности. Основные средства архитектурной выразительности сосредоточены в зоне главного входа и атриума. Проект интересен тем, что жесткие требования по инсоляции побудили архитекторов к поиску нестандартного объемнопространственного решения, которое выразилось в организации четырехцветного атриума. Фактически это минигород с центральной площадью, перекрытой атриумом, служащим одновременно рекреационной зоной и коммуникативным узлом, связывающим два отдельных блока: палатный и лечебно-диагностический. Дневной свет в помещении создает игру света, полутени и тени за счет разных участков неба в окнах. Однонаправленный свет из единственного источника лишен такой жизненной силы, будь то обычное окно или панорамное остекление. Функциональные связи между блоками осуществляются по подземному и двум надземным переходам. Пространство атриума перетекает в открытое пространство эксплуатируемой кровли над пищеблоком, что дает возможность в теплое время года использовать ее как фойе конференц-зала и рекреацию [7, с. 212].

Одной из существенных проблем детей, находящихся на реабилитационно-восстановительном лечении в клинических отделениях НПЦ, является длительное нахождение в условиях однообразной депривационной среды лечебного учреждения, что требует включения этих детей в активное социокультурное пространство различными психологическими и культурно-просветительскими средствами. Атриум играет роль общего вестибюля, фойе и прогулочной зоны для детей, находящихся на лечении. В нем расположены зимний сад, огромный аквариум с экзотическими видами рыб. Здесь проходят всевозможные праздники и концерты, перед детьми и родителями выступают клоуны, артисты эстрады, их сверстники из детских творческих коллективов Москвы, к Новому году устанавливается внушительных размеров елка.

Центр, впервые в России предназначенный для лечения и реабилитации детей, перенесших различные заболевания, учитывает возрастную дифференциацию: в палатах специально оборудованы игровые зоны и зоны личного пространства ребенка; выделены зоны для матери и ребенка.

Взаимодействие в социальном пространстве медицины в настоящее время приобретает новые оригинальные формы, реализуемые растущим и крепнущим волонтерским движением, активно развивается больничная клоунада. Приведем только один пример необычной, нетривиальной, хотя и не менее важной социальной поддержки нуждающихся. Для НПЦ медицинской помощи в Солнцево неравнодушными рукодельницами, объединившимися посредством акции «Поможем?!!! НПЦ», объявленной на сайте «Лоскутных дней круговорот», были созданы десятки детских одеял и игрушек в технике пэчворк [8]. Дело в том, что детям-пациентам, в силу их онкологических диагнозов, нельзя играть с обычными мягкими игрушками, сделанными из меха, велюра, плюша, а игрушки из х/б тканей врачами были одобрены, но такие игрушки не продаются в магазинах, их могли сделать только рукодельницы. Безусловно, такое предметное наполнение пространства создает позитивный настрой и радует детей.

Федеральный научно-клинический центр детской онкологии, гематологии и иммунологии им. Д. Рогачева, г. Москва, 2011 г. На сегодняшний день это самая крупная и наиболее технически оснащенная клиника Европы, рассчитанная на 220 коек. Ежегодно в Центр поступает до 2000 первичных пациентов, а общее число госпитализаций превышает 10000, выполняется до 200 трансплантаций костного мозга, что является одним из самых больших показателей не только в России, но и в мире [9].

Здание построено с использованием яркой графики и контраста объемов и форм фасадов. Главным архитектурным приемом, можно даже сказать, что в нем - душа этого медицинского комплекса, является радужное разноцветье. В нем смысл, заложенный архитекторами: радуга - символ надежды. Цвета радуги, будучи разбиты на фрагменты, например, в эркерах прямых медицинских корпусов в одном месте - в пансионате для выздоравливающих детей собираются, подобием букета, и возвращают радуге цельность. 


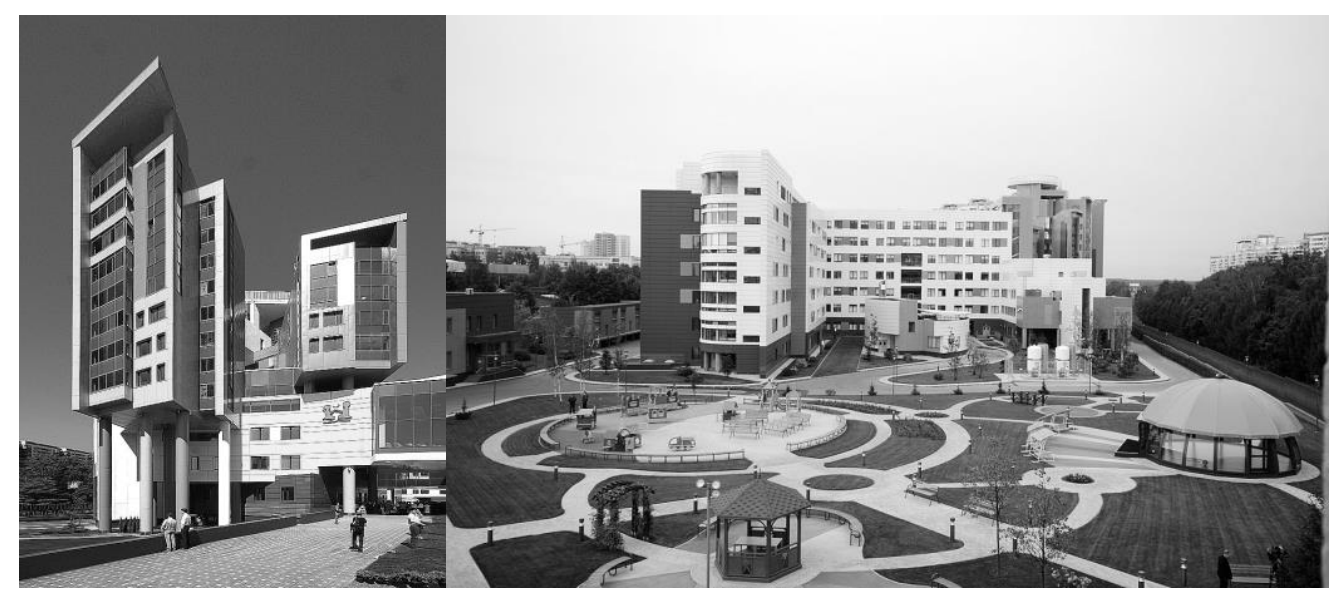

Рис. 2. ФГБУ «ФНКЦ ДГОИ им. Дмитрия Рогачёва»

За цветом следует форма - тоже собирается в пучок, теряет строгость, фокусируясь в одном месте, преобразует весь комплекс. Надежда на выздоровление - собрана в «Древе жизни» и бросает свои отблески на другие корпуса, обнадеживая малышей и их родителей, давая опору. Фактически, авторы попытались с помощью одного только искусства дать людям надежду или даже «подстегнуть» процесс выздоровления и перехода детей из пространства медицинских «балок» в «живой городок» [10].

Интерьеры здания также решены в комфортной для детей колористической и навигационной схеме. Дизайн больничных палат становится одним из катализаторов выздоровления - комнаты просторны и разноцветны, в каждой, помимо кровати ребенка, находится кровать для члена семьи, палаты оборудованы душевой кабиной и туалетом.

Проектируя больницу для детей с тяжелыми заболеваниями крови, архитектор Александр Асадов сработал примерно как Пэтч Адамс, самый известный в мире доктор-клоун. Собственно, он этого и не скрывал: «Архитектурное решение этого комплекса подсказали нам сами врачи - неравнодушные и творческие люди, которые попросили нас создать очень оптимистичное здание, ничем не напоминающее угрюмую больничную архитектуру», - пояснил архитектор [11].

Особого внимания заслуживает «Древо жизни» - это пансионат для пребывания больных и сопровождающих их родителей, способный принять до 150 семей, гостиничные функции в составе научноклинического центра у нас в стране были предусмотрены впервые. В каждой квартире-блоке предусмотрены три жилые комнаты с санузлами, каждая для одного ребенка и его мамы, общая гостиная и кухня.

В Центре функционирует отделение медицинской психологии и реабилитации, где пациенты получают помощь уже на ранних сроках терапии. Кроме того, в составе ФНКЦ ДГОИ им. Дмитрия Рогачева открыт лечебный реабилитационный научный центр «Русское поле» на базе реконструированного подмосковного санатория. Организовать подобную службу в высокоинтенсивном стационаре, когда ещё ментально родители борются за жизнь своих детей - нельзя, а вот в санатории, где уже идет борьба за здоровье, за восстановление, - просто необходимо.

Общественная и воспитательная деятельность организуется волонтерами, которые проводят мастерклассы, вместе с детьми они рисуют, играют в настольные игры, лепят из пластилина и смотрят фильмы. Всем этим они занимаются в большой игровой комнате, в самой больнице. Болезнь и длительное лечение в больнице не должны помешать ходу повседневной жизни, в которой значительную часть времени занимала школа и школьные друзья. В Центре в рамках проекта «Учим. Знаем» создана настоящая полноценная школа, позволяющая не только освоить школьную программу, но сдать ГИА и ЕГЭ, поучаствовать в различных творческих проектах.

Детский хоспис им. Анжелы Вавиловой в г. Казани, 2014 г. В ряде случаев, несмотря на все старания врачей, при наличии тяжелого заболевания, болезнь у ребенка приобретает необратимое течение. В таких случаях в мировой практике ребенок получает паллиативную помощь (от лат. pallium — покрывало, плащ, создание защиты от тягостных проявлений болезни) на дому или в хосписе - специализированном медикосоциальном учреждении. Хоспис предназначен для неизлечимых больных с целью обеспечения им симптоматического лечения, ухода, психосоциальной реабилитации, а также психологической поддержки родственников на период болезни и утраты ими близкого. Англичане, первыми в мире организовавшими детский хоспис в 1982 году, называют подобные заведения не hospes (от лат. - гостеприимство), a respice (от англ. respite - передышка), потому что «передышка», облегчение страданий нужны не только больным детям, но и их родителям.

Первым государственным учреждением в РФ паллиативной помощи детям и подросткам, страдающим неизлечимыми заболеваниями в терминальной стадии и коротким прогнозом жизни, стал СанктПетербургский детский хоспис в парке Куракина Дача, открытый в 2010 году. Но детский хоспис им. А. Вавиловой в Казани- первое в стране подобное учреждение, которое построено на деньги благотворителей и «де юре» зарегистрированное, не просто как медицинское учреждение, а как собственно «Детский хоспис». 


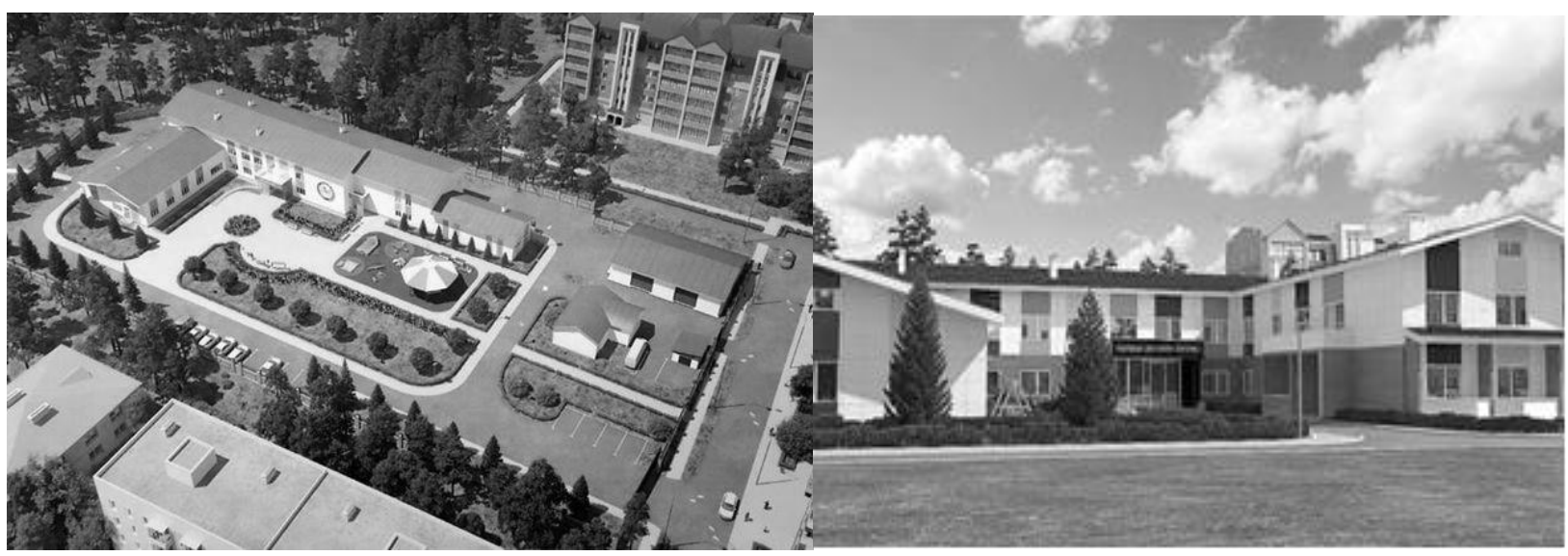

Рис. 3. Детский хоспис им. Анжель Вавиловой в г. Казани

Супруги Вавиловы, потерявшие ребенка, создали Фонд помощи детям, больным лейкемией, по их же инициативе был открыт детский хоспис, получивший имя их дочери, но сами они его называют «Дом Ангелов» [12]. Этот проект - удачный опыт частно-государственного финансового партнерства, реализованный с учетом всех самых современных медицинских технологий оказания паллиативной помощи. Впервые, помимо комфорта и уюта, создавались условия гуманной социальной микросреды, обеспечивающей оптимальные контакты в маленьком коллективе, окружающем больного ребенка. В этой связи учитывалось стремление больного к общению или изоляции, его потребности в смене впечатлений и настроений, в эстетическом окружении, в получении информации, в религиозных отправлениях, в чередовании покоя и деятельности. На территории построена уникальная детская игровая площадка с качелями, горками и каруселями, на которые можно въезжать даже на инвалидных креслах, призванная помочь исполнить детскую мечту играть вместе - вне зависимости от состояния здоровья.

Хотя медицинское обслуживание фокусируется на больном, но вся система ухода требует общения с семьей и другими близкими пациенту людьми. В связи с этим на территории предусмотрен гостиничный блок для проживания родителей, для того, чтобы иметь возможность помогать ребенку и быть с ним во время смерти. В хосписе создана специальная ритуальная комната, где родственники детей, ушедших из жизни, могли бы с ними достойно проститься, которая оформлена сдержанно, без привычного мрачного антуража, принятого в таких случаях. Предусмотрены в хосписе и молельные комнаты для обрядов разных вероисповеданий. Пожалуй, в хосписе время - это самый ценный ресурс, которым люди могут поделиться, подарить, разделить его с ребенком.

Следует отметить, что не только профессионалы разных сфер создают социальное пространство для медицинской деятельности, но и непосредственно сами субъекты взаимодействия, неравнодушные люди. Это значит, что врачи, медицинский персонал, психологи, учителя, волонтеры, родители и в немалой степени архитекторы решают общую задачу - улучшить качество жизни больных детей и их семей. В связи с тем, что изменилась идеологическая модель в обществе, система ценностей, меняется и само взаимодействие в социальном пространстве медицины и его отражение в архитектурном пространстве, где не сам по себе объект, а субъекты и их потребности становятся первостепенными.

Таким образом, архитектурное пространство для медицинской деятельности рассматривается нами как часть социального пространства медицины, предполагающим полифункциональное единство интроперсональных, групповых и институциональных уровней социального взаимодействия. Сегодня в России с учетом того, что больничная среда, окружающая ребенка, понимается как социальная ситуация психоэмоционального развития, архитекторами создаются комфортные объемно-планировочные решения медицинских учреждений. Среда, предназначенная для больных детей, различных по уровню развития, возрасту, требованиям душевного комфорта, должна быть разнообразна и иметь качества, соответствующие потребностям каждого ребенка. С помощью архитектурно-планировочных средств и дизайнерских решений предметно-пространственной среды решаются проблемы социокультурного порядка, связанные с психофизиологическим состоянием больного ребенка, направленные, прежде всего, на уменьшение тревог и болезненности лечения, создание условий, при которых не было бы унижения болью, страхом, обреченностью ни больного ребенка, ни тех, кто находится с ним рядом.

\section{Лumepamypa}

1. Назарова М. П., Барковская А. Ю., Янин К. Д. Социокультурные аспекты организации архитектурного пространства для медицинской деятельности. Вестник Волгоградского Государственного Университета. Серия 7. Философия. Социология и социальные технологии. Научно-теоретический журнал № 2 (28), 2015. C. 68-74. 
2. Выготский Л. С. Проблема развития высших психических функций / Л. С. Выготский // Собрание сочинений: В 6-ти т. Т. 3 Проблемы развития психики / Под ред. А. М. Матюшкина. М.: Педагогика, $1983.368 \mathrm{c}$.

3. Баранов А. А., Альбицикий В. Ю., Иванова А. А., Терлецкая Р. Н., Косова С. А. Тенденции заболеваемости и состояние здоровья детского населения Российской Федерации. Российский педиатрический журнал. № 6, 2012. C. 4-9.

4. Полунина Н. В. Состояние здоровья детей в современной России и пути его улучшения. Журнал Вестник Росздравнадзора. № 5, 2013. С. 17- 24. С. 21.

5. Мосин В. О. Архитектурная модернизация учреждений для детей-инвалидов: на примере Саратовской области: диссертация ... кандидата архитектуры: 05.23.21. [Место защиты: Нижегор. гос. архитектур.строит. ун-т]. Саратов, 2011. 165 с.: ил. С. 8-9.

6. Краткий психологический словарь / Ред. А. В. Петровский, М. Г. Ярошевский; ред.- сост. Л. А. Карпенко. Ростов-на-Дону: Феникс, 1998. 512 с.

7. Гайдук А. Р. Новая типология медицинских учреждений. Журнал «Молодой ученый», 2011. № 3. Т. 2. С. 212-216.

8. Лоскутных дней круговорот. [Электронный ресурс]. Режим доступа: http://vasiliya.ru/?page_id=525/ (дата обращения: 5.06.2014).

9. ФНКЦ детской онкологии, гематологии и иммунологии им. Д. Рогачева. [Электронный ресурс]. Режим доступа: http://www.fnkc.ru/index.jsp?load=facts/ (дата обращения: 26.08.2015).

10.Герасименко A. Разноцветная душа. [Электронный ресурс]. Режим доступа: http://archi.ru/russia/13961/raznocvetnaya-dusha/ (дата обращения: 18.02.2009).

11. Онкобольных детей будут лечить при помощи архитектуры. [Электронный ресурс]. Режим доступа: http://uaprom.info/news/107817-onkobolnyh-detej-budut-lechit-pri-pomowi-arhitektury-foto--ugmk-info-.html/ (дата обращения: 30.06.2011).

12. В Татарстане открылся «Дом ангелов». [Электронный ресурс]. Режим доступа: http://intertat.ru/ (дата обращения: 03.06.2014). 